\title{
UNDERGROUND AIR DUCT TO CONTROL RISING MOISTURE IN HISTORIC BUILDINGS: IMPROVED DESIGN AND ITS DRYING EFFICIENCY
}

\author{
JiŘí PAZDERKA, Eva HÁJKOVÁ*, MARTin JiRÁNEK \\ Department of Building Structures, Faculty of Civil Engineering, CTU in Prague, Thákurova 7, 16629 Prague, \\ Czech Republic \\ * corresponding author: eva.hajkova@fsv.cvut.cz
}

\begin{abstract}
The underground air ducts along peripheral walls of a building are a remediation method, which principle is to enable an air flow along the moist building structure's surface to allow a sufficient evaporation of moisture from the structure. This measure reduces the water transport (rising moisture) into the higher parts of the wall where the high water content in masonry is undesirable. Presently, underground air ducts are designed as masonry structures, which durability in contact with ground moisture is limited. The article describes a new design of an underground air duct, which is based on specially shaped concrete blocks (without wet processes, because the blocks are completely precast). The air duct from concrete blocks is situated completely below the ground surface (exterior) or below the floor (interior). Thanks to this, the system is invisible and does not disturb the authentic look of rehabilitated historic buildings. The efficiency of the air duct technical solution was verified by the results of tests (based on the measured moisture values) conducted on a laboratory model. The experimental study showed that the moisture in the masonry equipped with the presented underground air duct had decreased considerably compared to the reference sample, namely by $43 \%$ on average. The experimental study was numerically validated through numerical simulations performed with the program WUFI 2D.
\end{abstract}

KEYWORDS: moisture; masonry; refurbishment; air ducts; drying.

\section{INTRODUCTION}

An increased moisture content of masonry structures always had a negative impact on the utility value of the particular building. This constitutes a serious problem in the reconstruction of historic buildings and its solution requires a comprehensive and highly professional approach. In historic structures, the increased moisture of vertical masonry structures occurs rather often. This phenomenon is attributable to the absence or the poor function of the waterproofing envelope of the substructure [1, 2]. As a rule, a higher masonry moisture is manifested by distinct moist patches on wall surfaces, or even by a surface layer disintegration (Fig. 1). Most frequently, a plaster degradation followed by a degradation of the building material and mortar is caused by the crystallisation pressure of soluble salts in masonry or a repeated freezing of the damp structure 3. Increased moisture levels result in changes in mechanical and physical properties [4-7] (e.g., modulus of elasticity and strength), which may lead to a reduced load carrying capacity of masonry structures [8, 9]. Another adverse effect, attributable to a higher moisture, is the deterioration of thermal insulation properties of masonry leading to a higher thermal conductivity. A specific problem is the growth of microorganisms and moulds on damp wall surfaces, causing an unhealthy environment within the building.

Additional protection of historic buildings against ground moisture and subsurface water can be per-

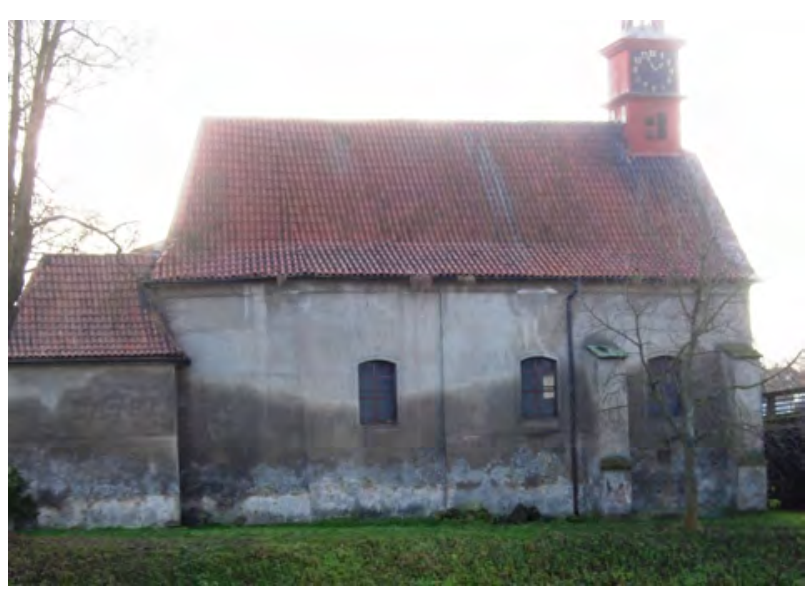

FIGURE 1. Long-term effect of rising moisture (unmaintained historic building) — Church of St. Catherine (built in 1315, modified in 19th century), Havlickuv Brod, CZ.

formed by several remediation methods. The final remediation measure is typically a set of more methods (the aim is also the elimination of other negative influences 10, 11]). The main task of the rehabilitation method described in this article is a significant increase of the evaporation of moisture from the historic masonry structure. The influence of the salts was not considered, although it is known that it can be important. It is a parameter to consider in future works. 


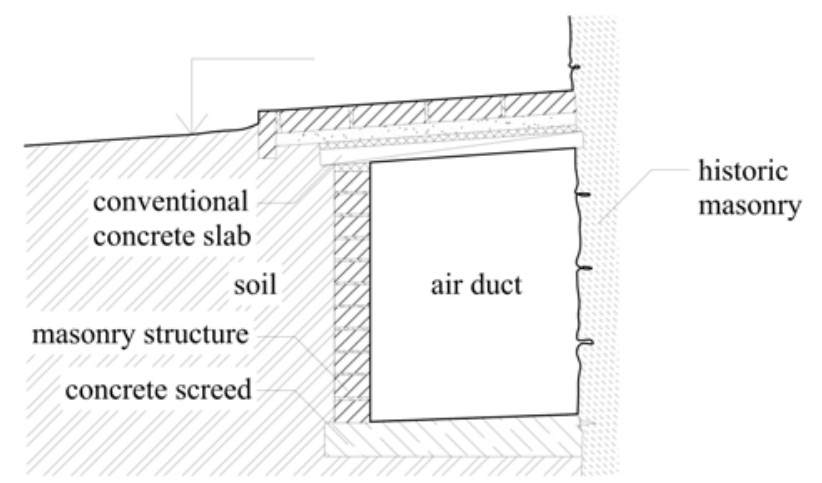

Figure 2. The traditional air cavity based on a masonry structure.

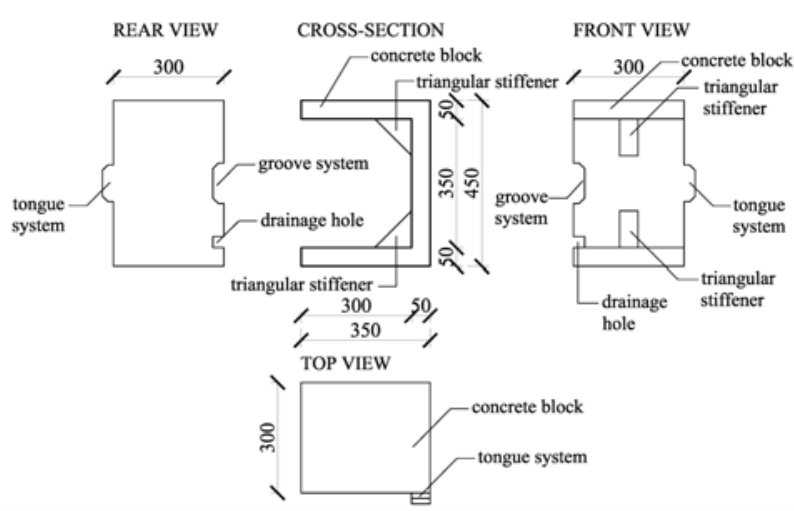

FiguRE 3. A specially shaped concrete block.

\subsection{The PRINCIPLE OF UnDERGRound AIR DUCTS}

Air cavities are a remediation method, whose basic principle is to enable an air flow along the surface of moist structures to ensure a sufficient evaporation of moisture from the structure. The subsequently described air duct, which is installed along the perimeter walls of historic buildings, is one of these methods. A system based on a similar principle has been experimentally verified on limestone walls with a thickness of $20 \mathrm{~cm} \mathrm{[12,} \mathrm{13].} \mathrm{In} \mathrm{that} \mathrm{case,} \mathrm{however,} \mathrm{there} \mathrm{was} \mathrm{an}$ air duct made of cement blocks on both sides of the outer wall masonry. Ventilated underground ducts also enable protection of the building against external degradation processes.

Therefore, the structure of the air duct itself must be very durable. Air ducts, which are situated in the ground, are most often designed as a masonry structure in combination with a traditional concrete slab and concrete screed (Fig. 2). These structures are characterized by their high laboriousness (brickwork, concreting), but the main problem is a high risk of low durability arising from the structure contact with the ground moisture and also with a high level of air humidity inside the duct. It is evident that the durability of the traditional air duct (based on the masonry) is limited.

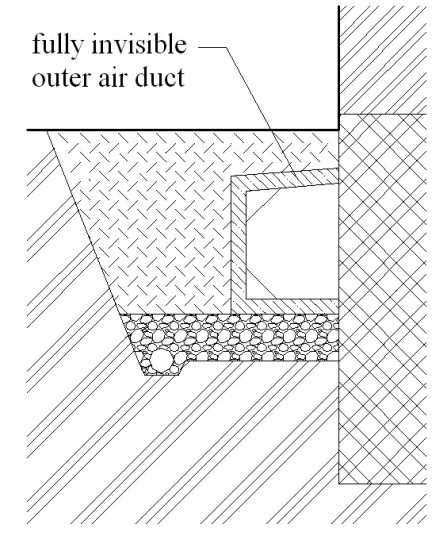

Figure 4. Air duct (concrete blocks) installed into a historic masonry building.

\section{MATERIALS AND METHOD}

\subsection{Air DuCt BASED ON CONCRETE Blocks}

The weaknesses of traditional air ducts (arising from their structural and material design) should be eliminated by a special set of concrete blocks presented below. The blocks are designed with the aim of achieving a high durability and simplicity of the installation. The system consists of a special set of concrete blocks in the shape of a letter "C" (Fig. 3). The blocks are placed side by side along the walls of the refurbished building and create a continuous cavity. Air ducts can be applied on either the outer (exterior) or inner (interior) side of outer walls (Fig. 4). The application of a ventilated cavity on the interior side of masonry walls is highly invasive and it might be unfeasible for some historic buildings, as it requires dismantling of the floor. In such cases, only the exterior ventilation shaft can be installed.

The blocks are equipped with a tongue and groove system (on their sides). The purpose of these elements is to ensure the equitable settlement of the entire system (the blocks "cooperates"). The installation of the system should be possible by manual handling only. For this reason, the dimensions of the blocks are limited (optimally to $0.35 \times 0.45 \times 0.3 \mathrm{~m}$, which results in $37 \mathrm{~kg}$ in weight). During heavy rains, water can leak inside the duct - for this case, the block is equipped with a small drainage hole in the bottom part. The system also contains special shaped blocks, which are adapted to use at corners etc.

The durability of the concrete blocks has to be ensured by designing the concrete composition at a relevant environmental influence degree under EN 206 14. It could be ensured, for example, by the use of a crystalline admixture inside the concrete [15-17]. This way of concrete improvement should ensure a complete waterproof concrete structure [18, 19]. It was also confirmed by many independent test labs [2024 .

A sufficient velocity of an air flow is necessary for a proper function of the ventilated duct. The design 


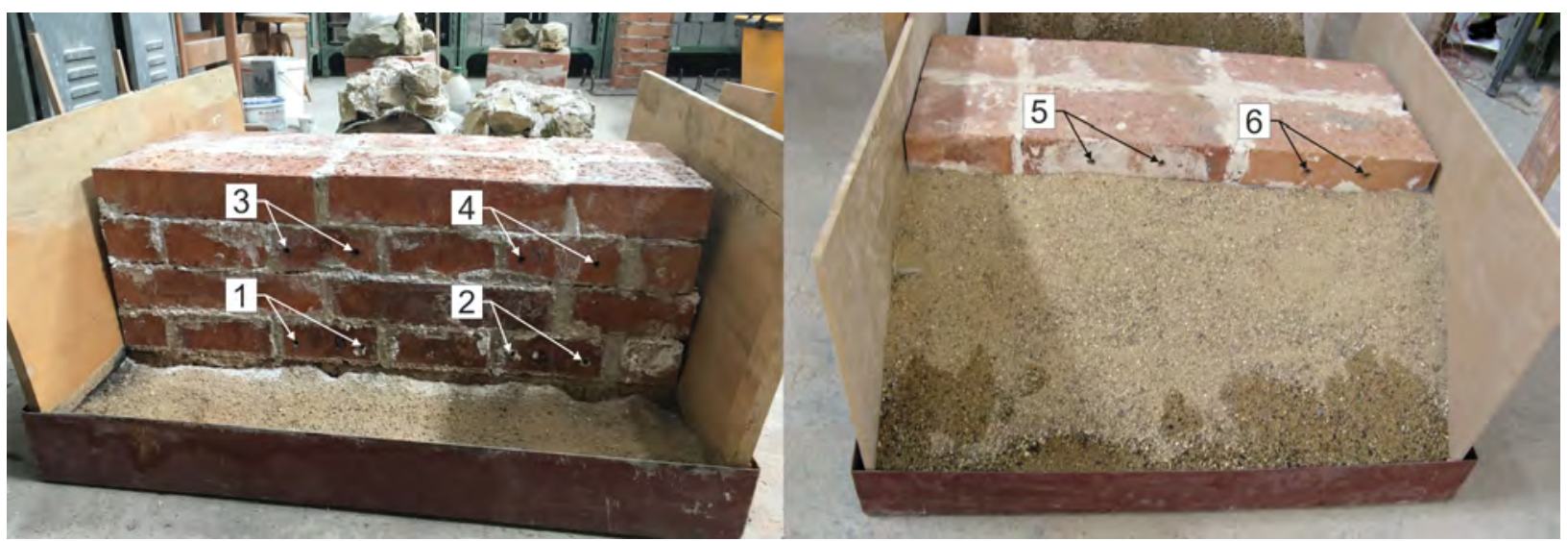

Figure 6. Placement of measuring points in masonry (on the laboratory model).

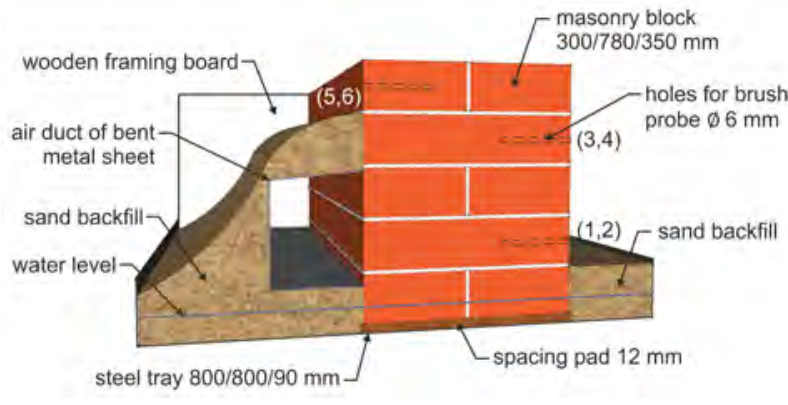

Figure 5. Laboratory model.

and placement of ventilation holes are, therefore, extremely important. Correctness of the design must be verified by a numerical calculation/simulation of the air flow in the duct and subsequently confirmed by a measurement. If a sufficient air flow rate is not measured in the piping, the required flow rate has to be provided by means of a fan. Therefore, the technical solution was analysed on a laboratory model $(\S(4)$ and by a numerical simulation $(\S 5)$.

\subsection{THE DRYING EFFICIENCY OF THE PRESENTED AIR DUCT - EXPERIMENTAL STUDY}

An experimental analysis of the efficiency of the ventilated duct was made in spite of the fact that the above technical design does not aim at outperforming current design solutions in their effect on reducing moisture in masonry (it outperforms them with its greater durability and ease and speed of execution).

The laboratory model (Fig. 5 of the above mentioned technical solution has been created (an air duct near the peripheral wall). The aim was to analyse the impact of this structural measure to the moisture level in the wall. The model simulated the peripheral wall of a historic building (thickness $600 \mathrm{~mm}$ ) from classic solid bricks, but in a reduced scale of $1: 2$ (the number of joints between the bricks have been overlooked).

\subsection{LABORATORY TESTING}

The first step in the experiment was to make the laboratory model itself. Historic bricks of format $290 \times 140 \times 65 \mathrm{~mm}$ and a historic lime mortar were used for the model. Table 1 shows the properties of the respective materials: brick and lime mortar. All properties (except specific heat) were experimentally determined in the Experimental Centre at CTU in Prague, in accordance with the respective European Standard [25] 28].

The dimensions of the simulated perimeter wall were $300 \times 780 \times 350 \mathrm{~mm}$. The concrete ventilated duct was simulated by using a metal sheet, which was shaped into a precise shape according to scheme on Figure 5 The whole set was installed into a "steel bath" and backfilled by the fine aggregate (simulating terrain). A constant level of water in the embankment and in lower part of masonry $(50 \mathrm{~mm}$ above the bottom of "steel bath") was kept constantly.

The simulation of the duct by using a shaped metal sheet was not a significant problem, because the aim of the measurement was to analyse the reduction of the moisture level in the masonry (not in the structure of the duct). The second reference model was created without a ventilated duct.

An electrical resistivity moisture meter was used for the measurement of the moisture level in the masonry. The measurement was performed using two probes applied into the holes drilled in the masonry. The principle of the masonry moisture measurement using an electrical resistivity moisture meter is described in detail in [30]. The measuring points (holes) were placed in the model as shown in Figure 6 Samples were extracted from the masonry after the end of the testing for a weight analysis. The samples were taken from the places where the holes for probes were located. Thereby, the values measured by the electrical resistivity moisture meter have been validated.

The highest moisture level in the masonry, due to the capillary attraction, can be expected at the centre of the wall [29. Therefore, the probes (sensors) were placed approximately $100 \mathrm{~mm}$ below the surface of the masonry. The masonry blocks were vapour-tightly 


\begin{tabular}{lcc}
\hline Material & Brick & Lime mortar \\
\hline Bulk density $\varrho$ & $1670 \mathrm{~kg} / \mathrm{m}^{3}$ & $1650 \mathrm{~kg} / \mathrm{m}^{3}$ \\
Heat capacity $c$ & $920 \mathrm{~J} / \mathrm{kg} \mathrm{K}$ & $840 \mathrm{~J} / \mathrm{kg} \mathrm{K}$ \\
Porosity $\varepsilon$ & $37.50 \%$ & $37.70 \%$ \\
Thermal conductivity $\lambda$ & $0.84 \pm 0.025 \mathrm{~W} / \mathrm{m} \mathrm{K}$ & $0.67 \pm 0.009 \mathrm{~W} / \mathrm{m} \mathrm{K}$ \\
Vapour diffusion resistance factor $\mu$ & & \\
$\quad$ dry cup & 19.5 & 8.9 \\
$\quad$ wet cup & 14.7 & 4.3 \\
Water absorption coefficient $A$ & $0.19 \pm 0.002 \mathrm{~kg} /\left(\mathrm{m}^{2}\right)$ & $0.22 \pm 0.006 \mathrm{~kg} /\left(\mathrm{m}^{2}\right)$ \\
Freewater saturation $w_{\text {sat }}$ & $370 \mathrm{~kg} / \mathrm{m}^{3}$ & $359 \mathrm{~kg} / \mathrm{m}^{3}$ \\
\hline
\end{tabular}

TABLE 1. Material properties.

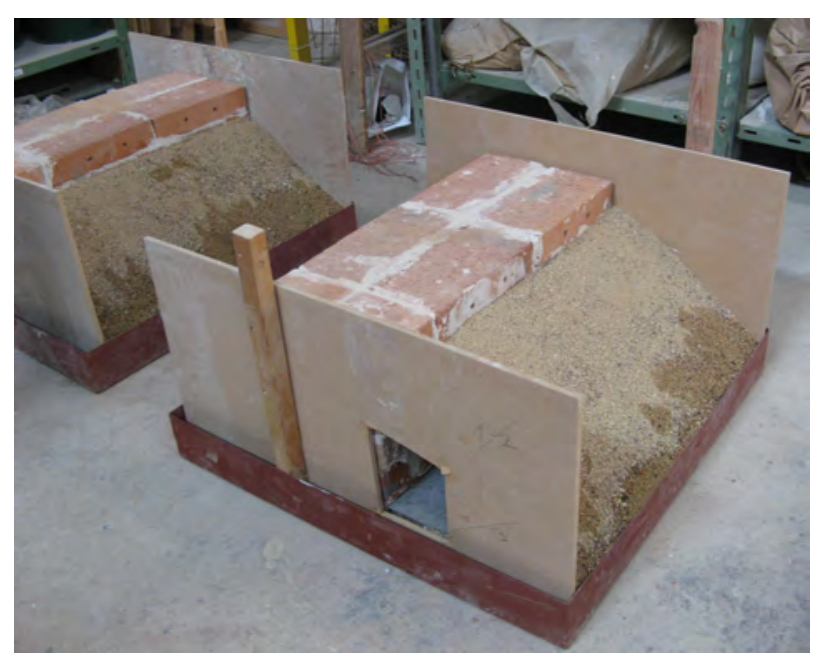

FiguRE 7. Assembled models in laboratory.

closed on the sides (simulation of the continuation of the wall) in order to regard the masonry model as a $2 \mathrm{D}$ problem. After its completion, the models were kept in the laboratory for three months for achieving a stable level of moisture in the masonry (Fig. 7).

\subsection{ArRAngement of the test}

The first three months after the completion of models, the air flow inside the duct was not activated. The saturation of the masonry by rising water has been reached during this period of time.

In the fourth month after the completion of the models, the flowing air in the duct was created by a fan (Fig. 8a) with a very low speed of the air flow $(0.05 \mathrm{~m} / \mathrm{s})$ through a fabric, which covered the inlet opening. This value is determined based on results of the calculation model that simulated a natural air flow in an exterior cavity applied to a real historical building [31. In case the required wind flow rate is not achieved in the cavity after the whole system in a real building is completed, the required air flow rate can be additionally provided by means of a fan. The air flow in the cavity is important because this allows that the relative humidity in the duct does not reach a value of $\varphi=100 \%$ (due to the transfer of water vapour from the masonry). It is also important that the incoming air should have the lowest possible relative humidity $\varphi[\%]$. The influence of the salts was not considered, although it is known that it can be important. Salts may negatively affect the masonry surface structure in the course of evaporation of salt-containing water. However, crystallisation of salt on a remediated building takes place before the remediation itself in places above the ground. After the remediation, the salt crystallisation area only shifts lower down into the ventilated cavity area, which is also more convenient in aesthetic terms.

The air cavity was maintained ventilated using a fan for a period of 3 months. The moisture measurement results obtained in the first month are only informative. The effects of the flowing air on the masonry moisture reduction are negligible in such short time. Therefore, the results of this initial measurement are not included in the final evaluation. Seven moisture measurements were made at an interval of 10 days during the next two months, when the fan was installed to the air cavity (Fig. 8b). The moisture was measured using the electrical resistivity moisture meter. In addition, the relative humidity of air and temperature were measured in the laboratory and inside the air duct. The relative air humidity measured within the cavity was $41.7 \pm 2 \%$, whilst the humidity of the air in the lab was $39.1 \pm 2 \%$. The air temperature in the lab was $23 \pm 1^{\circ} \mathrm{C}$.

\section{Results AND DiscUSSION}

The main benefit of the measurement was the possibility of an accurate comparison between the same structures (under the same conditions) with and without the ventilated duct. The impact of the ventilated duct was expressed as the percentage decrease in the bulk moisture of the masonry, which was measured in the same places in both models. Results of measurements in all measured points are shown in Table 2. The presented values were measured at an air velocity of $0.05 \mathrm{~m} / \mathrm{s}$. The results demonstrated the effectiveness of the air duct - the decrease of moisture level in the masonry was, on average, $43 \%$.

The following charts show the rate of the moisture decrease in the individual measuring points (Fig. 9). The initial moisture content in the masonry blocks 

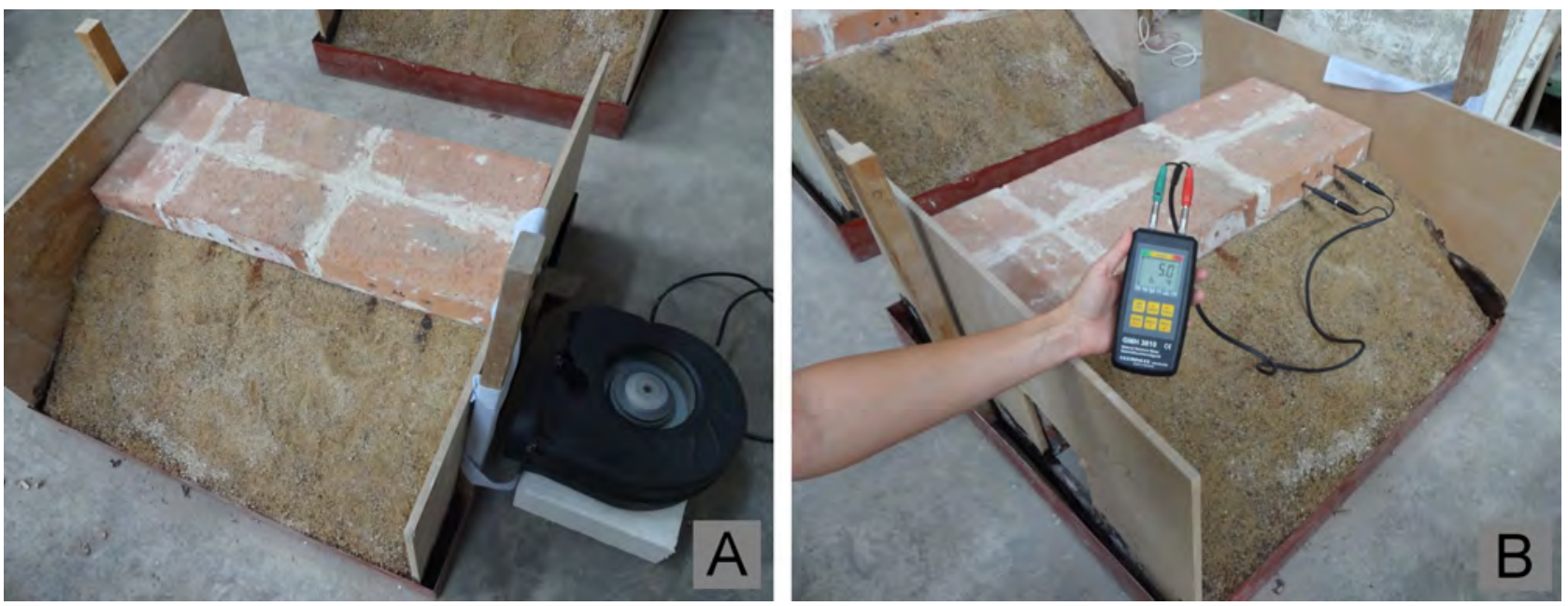

Figure 8. (a) Fan providing an air flow in the duct. (b) Measurements made by using of electrical resistivity method.

\begin{tabular}{cccc}
\hline $\begin{array}{c}\text { Measuring } \\
\text { points }\end{array}$ & \multicolumn{2}{c}{ Mean values of the bulk moisture $w[\%]$} & $\begin{array}{c}\text { Value of moisture } \\
\text { reduction }\end{array}$ \\
\cline { 2 - 3 } & Reference sample & Sample with air duct & \\
\hline 1 & 21.2 & 20.1 & $5.19 \%$ \\
2 & 21.0 & 18.3 & $12.86 \%$ \\
3 & 16.5 & 7.8 & $52.73 \%$ \\
4 & 10.5 & 6.2 & $40.95 \%$ \\
5 & 9.9 & 2.1 & $78.79 \%$ \\
6 & 7.0 & 2.1 & $70.00 \%$ \\
\hline
\end{tabular}

TABLE 2. The final values of the moisture readings $w$ [wt.\%], after 3 months of ventilation using a fan with the air velocity of $0.05 \mathrm{~m} / \mathrm{s}$.

after the saturation with rising water for a period of 3 months (without using a fan, an air flow did not occur) is shown at the time 0 . Values of the moisture measurements during the next two months carried out every 10 days, when the fan was installed to the air duct, are shown for the times 30-90 days. In the charts, for the measuring points 1 and 2 , the bulk moisture value of $21.3 \%$, indicating the highest water absorption of the brick (percent by mass) determined by gravimetry is, marked. It is evident that the moisture content in points 1 and 2 of the reference sample reached its maximum. Moisture values in these two points are almost the same for the reference sample and for the sample with the air cavity. These measuring points are only $60 \mathrm{~mm}$ above the water level, and thus the effect of the cavity cannot occur here. The effect of the air cavity is evident at the measuring points above the air cavity.

The final charts summarize the values of the moisture measured at individual points for the reference model and the model with the air duct. The first chart shows the values of moisture at the beginning of the measurement after 30 days of using the fan (Fig. 10). The second chart shows the final values of the moisture after 90 days from the fan involvement (Fig. 11). The experimental analysis results show that the air cavity described above is effective in reducing the moisture in masonry under the condition that an air flow is provided in the cavity (by a natural ventilation process or by installing mechanical ventilation device).

\section{Verification of the test RESULTS — NUMERICAL SIMULATION}

\subsection{Simulation program USEd and VALIDATION}

The experimental study was numerically validated through numerical simulations performed with the program WUFI 2D. This software, developed at the Fraunhofer Institute for Building Physics (Germany), permits an assessment of changes in the moisture content and temperature inside structures depending on interior and exterior climatic conditions [32 34]. The use of the software for the numerical simulation requires knowledge of boundary conditions and thermal and moisture-related properties of the materials used [35, 36. In this case, we used the thermal and moisture-related material properties determined experimentally in the laboratory study (see 4.3 above). In addition, we entered the boundary conditions, the relative air humidity and air temperature in the laboratory and the test duration. All these values were the same as in the laboratory experiment described above. The numerical simulation was made for a reference sample and a sample with an air duct. 

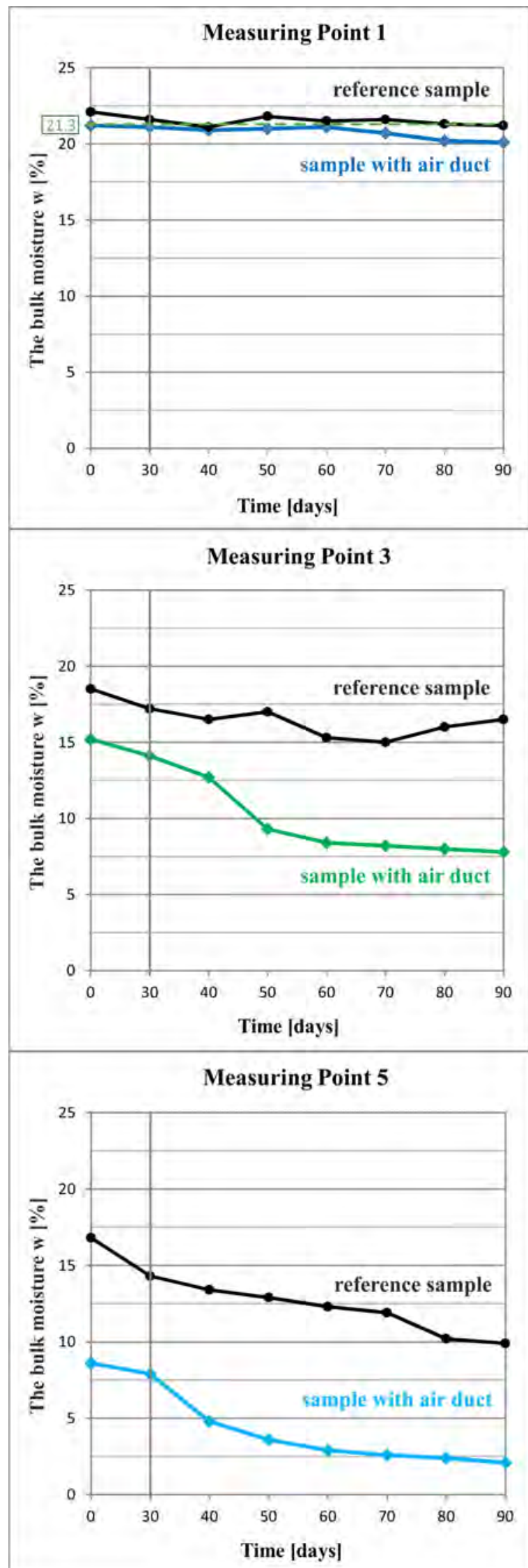
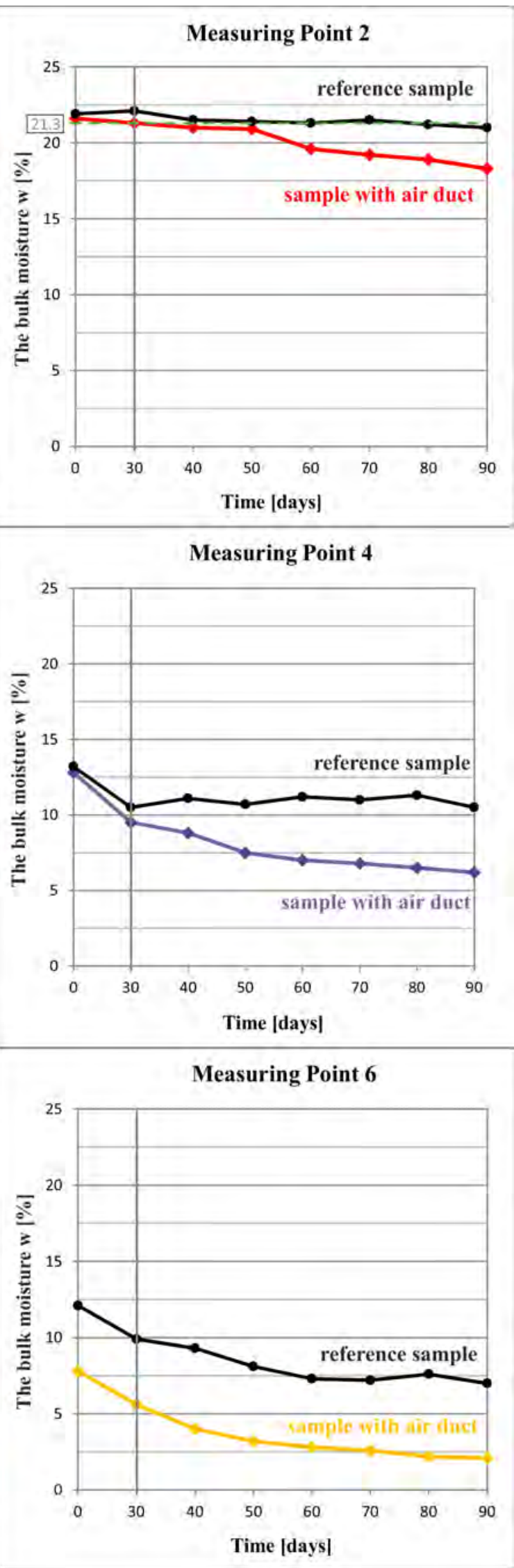

Figure 9. The measured values of moisture in the individual measurement points. 


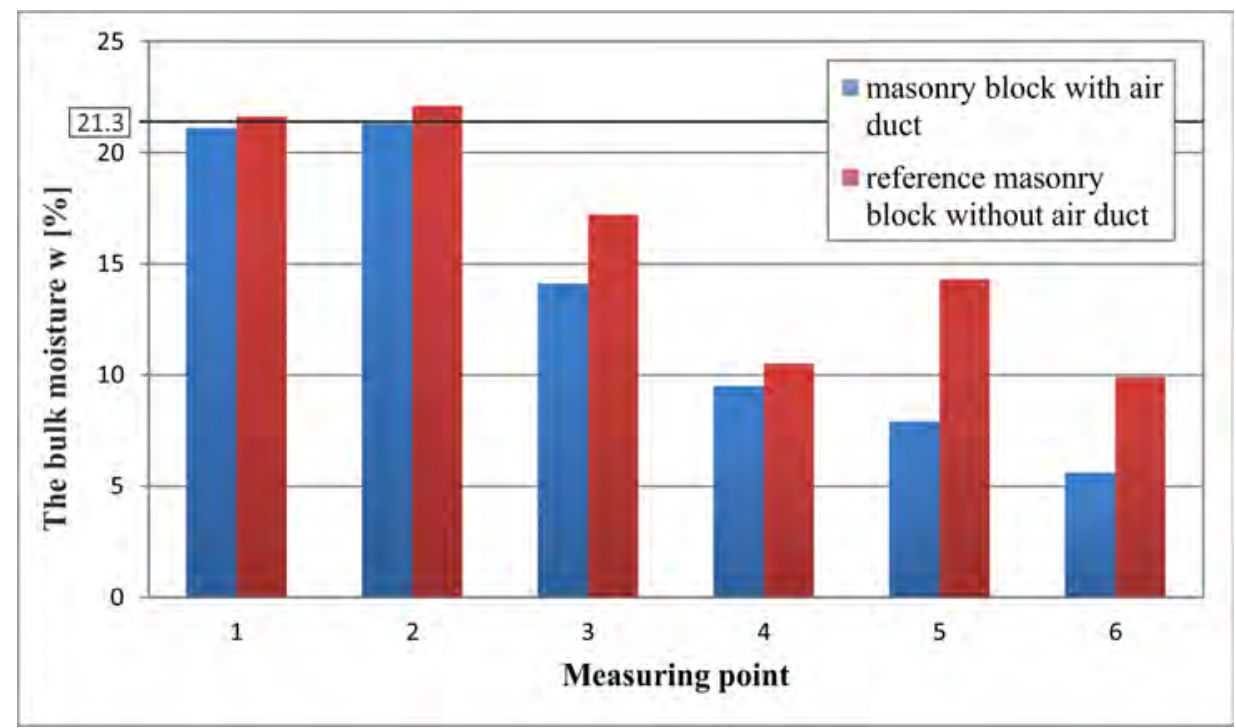

FigurE 10. The measured values of moisture after 30 days of using the fan.

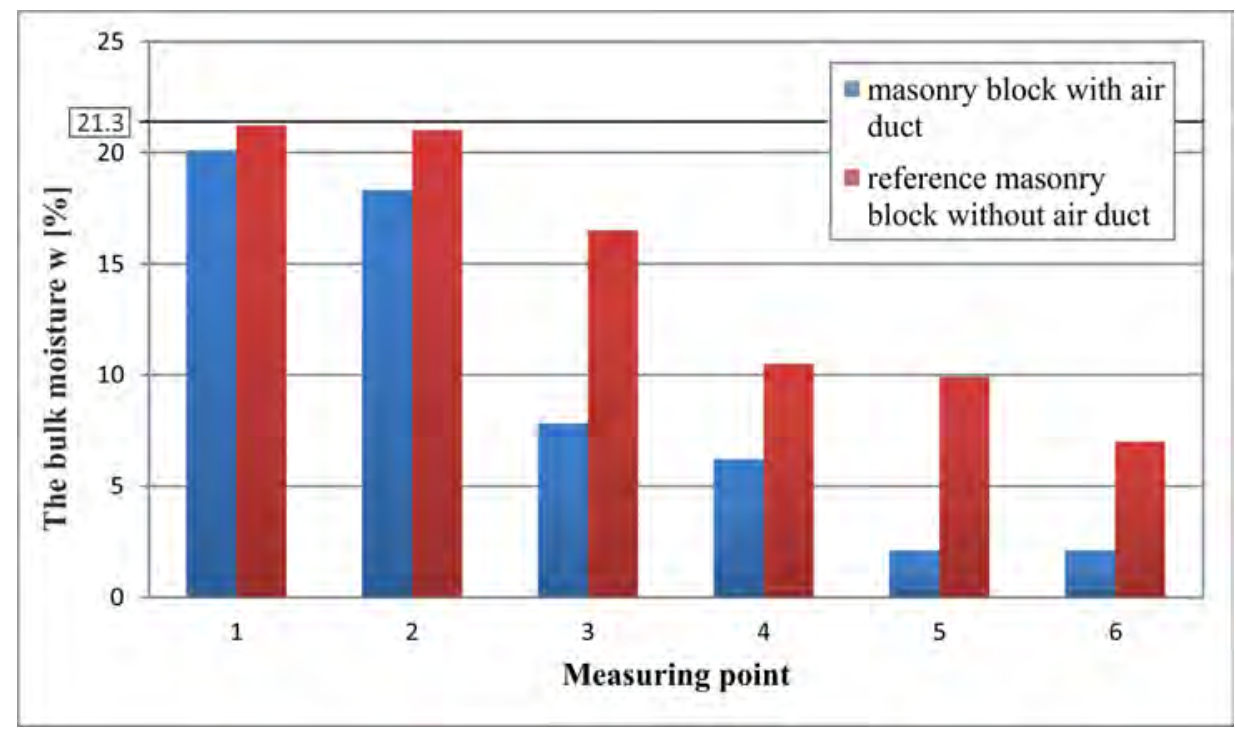

Figure 11. The final values of moisture after 90 days of using the fan.

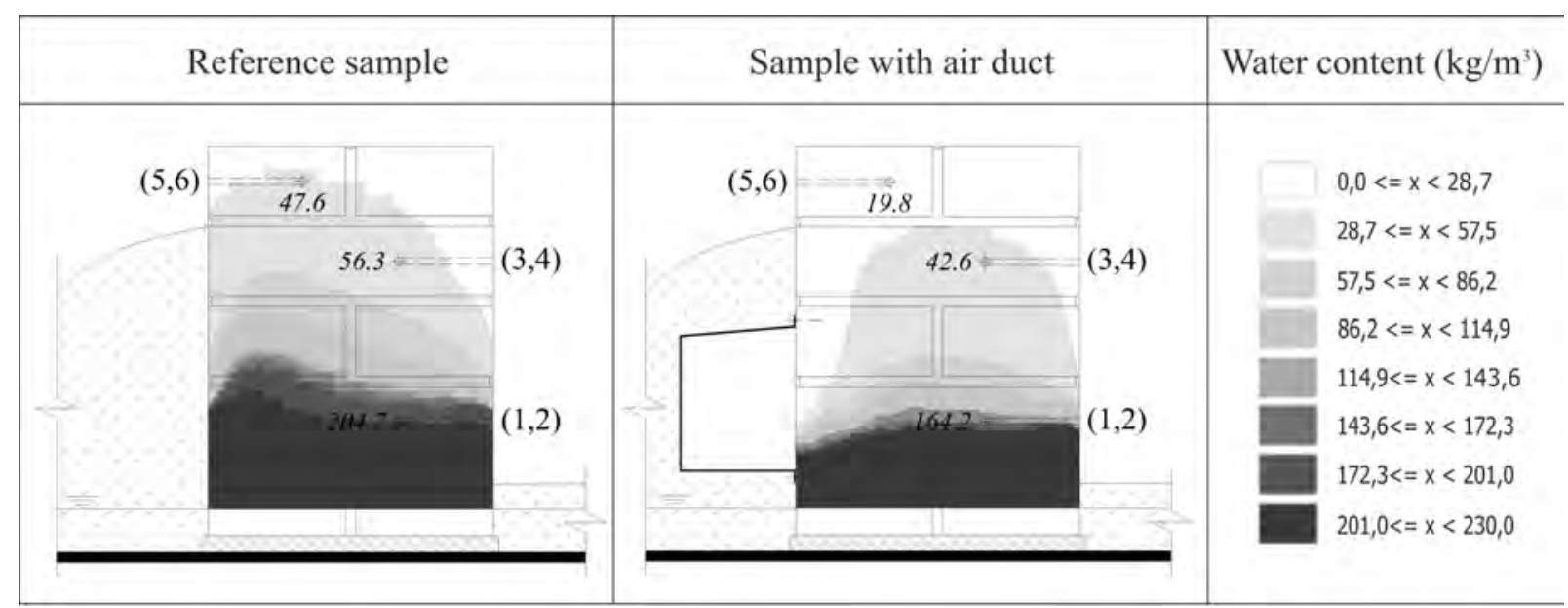

FIGURE 12. The results of the numerical simulation (created in WUFI 2D). 


\subsection{Results AND Discussion}

The results of the numerical simulation showed that, like in the laboratory experiment, the total water content in a brick block equipped with an air duct decreases. As it is evident from the resulting water content and the overall picture of the moisture trend in the samples, the masonry dries at the air duct location due to an increased evaporating surface and due to the air flow in the duct (Fig. 12). When compared to the reference sample, the moisture front in the sample with the air duct was lower. We can, therefore, conclude that the simulation of a behaviour of test blocks using the calculation software was identical to the behaviour of test blocks in the experimental study.

\section{Conclusions}

The results of the experimental measurement on laboratory models (verified by a simulation using a software) demonstrated that an air duct based on concrete blocks has a great potential in the field of moist buildings rehabilitation. Unlike conventional air ducts (based on masonry structures), it is a much simpler solution (less laboriousness) and with a higher durability. The results of laboratory tests demonstrated the effectiveness of the air duct - the decrease of the moisture level in the masonry was, on average, $43 \%$ (in comparison with the reference model without an air duct). The simulation of the behaviour of the laboratory models using a calculation software was identical to the behaviour of the test blocks in the laboratory.

\section{ACKNOWLEDGEMENTS}

This work was supported by the Czech Ministry of Education, Youth and Sports under the grant no. SGS17/117/OHK1/2T/11 (provided within institutional support for CTU in Prague).

\section{REFERENCES}

[1] Piaia, J.C.Z. et al.: Measurements of water penetration and leakage in masonry wall: Experimental results and numerical simulation. Building and Environment, 61, 2013, p. 18-26. DOI:10.1016/j.buildenv.2012.11.017

[2] Janssen, H., Derluyn, H., Carmeliet, J.: Moisture transfer through mortar joints: A sharp- front analysis. Cement and Concrete Research, 42(8), 2012, p. 1105-1112. DOI:10.1016/j.cemconres.2012.05.004

[3] Künzel, H. M.: Simultaneous heat and moisture transport in building components: One- and two-dimensional calculation using simple parameters. Dissertation, University of Stuttgart, Stuttgart, Germany, 1994.

[4] Sykora, J. et al.: Computational homogenization of non-stationary transport processes in masonry structures. Journal of Computational and Applied Mathematics, 236(18), 2012, p. 4745-4755. DOI:10.1016/j.cam.2012.02.031
[5] Larsen, P. K.: Determination of water content in brick masonry walls using a dielectric probe. Journal of Architectural Conservation, 18(1), 2012, p. 47-62. DOI:10.1080/13556207.2012.10785103

[6] Hettmann, D.: Zur Beeinflussung des Feuchte und Salzgehaltes in Mauerwerk. Bautenschutz und Bausanierung, 16(5), 1993, p. 72-75.

[7] D'Agostino, D.: Moisture dynamics in a historical masonry structure: The cathedral of Lecce (south Italy). Building and Environment, 63, 2013, p. 122-133. DOI:10.1016/j.buildenv.2013.02.008

[8] Witzany, J., Zigler, R.: Failure mechanism of compressed reinforced and non-reinforced stone columns. Materials and Structures, 48(5), 2015, p. 1603-1613. DOI:10.1617/s11527-014-0257-z

[9] Han, B., Wang, T.: Influence of water content on brick masonry's shear strength. Journal of Beijing Jiaotong University, 35(1), 2011, p. 1-5.

[10] Jiranek, M.: Sub-slab depressurisation systems used in the Czech Republic and verification of their efficiency. Radiation Protection Dosimetry, 162(1-2), 2014, p. 64-67. DOI:10.1093/rpd/ncu219

[11] Grytli, E. et al.: The impact of energy improvement measures on heritage buildings. Journal of Architectural Conservation, 18(3), 2012, p. 89-106. DOI:10.1080/13556207.2012.10785120

[12] Torres, I. M.: Wall base ventilation system to treat rising damp: The influence of the size of the channels. Journal of Cultural Heritage, 15(2), 2014, p. 121-127. DOI:10.1016/j.culher.2013.03.005

[13] Torres, I. M., De Freitas, V. P.: Treatment of rising damp in historical buildings: wall base ventilation. Building and Environment, 42(1), 2017, p. 424-435. DOI:10.1016/j.buildenv.2005.07.034

[14] EN 206 Concrete - Specification, performance, production and conformity. Brussels: European Committee for Standardization, 2014.

[15] Rahhal, V. et al.: Scheme of the Portland cement hydration with crystalline mineral admixtures and other aspects. Silicates Industriels, 74(11), 2009, p. 347-352. Scopus: 2-s2.0-73649090808.

[16] Pazderka, J.: Concrete with crystalline admixture for ventilated tunnel against moisture. Key Engineering Materials, 677, 2016, p. 108-113. DOI:10.4028/www.scientific.net/KEM.677.108

[17] Scancella, T., Robert, J.: Use of Xypex admixture to concrete as an inhibitor to reinforcement steel corrosion. Proceedings of the Materials Engineering Conference, 2, 1996, p. 1276-1280. Scopus: 2-s2.0-0030401904.

[18] Dao, V.T.N. et al.: Performance of permeability-reducing admixtures in marine concrete structures. ACI Materials Journal. 107(3), 2010, p. 291-296. WOS: 000278352700010

[19] Reiterman, P., Pazderka, J.: Crystalline Coating and Its Influence on the Water Transport in Concrete. Advances in Civil Engineering, 2016 (2016) 2513514. DOI:10.1155/2016/2513514 
[20] Reiterman, P., Bäumelt, V.: Long-term sorption properties of mortars modified by crystallizing admixture. Advanced Materials Research, 1054, 2014, p. 71-74. DOI:10.4028/www.scientific.net/AMR.1054.71

[21] Weng, T.L., Cheng, A.: Influence of curing environment on concrete with crystalline admixture. Monatshefte fur Chemie, 145(1), 2014, p.195-200. DOI:10.1007/s00706-013-0965-z

[22] Zhou, M.R. et al.: Study on experiment of concrete compounding XYPEX and steel fiber. Applied Mechanics and Materials, 105-107, 2012, p. 1755-1759. DOI:10.4028/www.scientific.net/AMM.105-107.1755

[23] Munn, R.L., Kao, G., Chang, Z.T.: Performance and compatibility of permeability reducing and other chemical admixtures in Australian concretes. Proceedings of 7th CANMET/ACI Int. Conference on superplasticizers and other chemical admixtures in concrete, 2003, p. 361-379.

[24] Bohus, S., Drochytka, R.: Cement based material with crystal-growth ability under long term aggressive medium impact. Applied Mechanics and Materials, 166-169, 2012, p. 1773-1778.

DOI:10.4028/www.scientific.net/AMM.166-169.1773

[25] EN ISO 10456 Building materials and products Hygrothermal properties - Tabulated design values and procedures for determining declared and design thermal values. Brussels: European Committee for Standardization, 2007.

[26] EN ISO 12571 Hygrothermal performance of building materials and products - Determination of hygroscopic sorption properties. Brussels: European Committee for Standardization, 2013.

[27] EN ISO 12572 Hygrothermal performance of building materials and products - Determination of water vapour transmission properties. Brussels: European Committee for Standardization, 2001.
[28] EN ISO 15148 Hygrothermal performance of building materials and products - Determination of water absorption coefficient by partial immersion, Brussels: European Committee for Standardization, 2002.

[29] De Freitas, V. P., Abrantes, V., Crausse, P.: Moisture migration in building walls - analysis of the interface phenomena. Building and Environment, 31, 1996, p. 99-108. DOI:10.1016/0360-1323(95)00027-5

[30] Pazderka, J., Hajkova, E.: Analysis of moisture in masonry. Building engineer, 89(9), 2014, p. 20-24. Scopus: 2-s2.0-84916933495.

[31] Tazky, L., Sedlakova, A.: Design of the ventilated air channel to resolve moisture problems in the historical church. Energy Procedia, 78, 2015, p. 1323-1328. DOI:10.1016/j.egypro.2015.11.148

[32] De Vries, D.: The theory of heat and moisture transfer in porous media revisited. Journal of Heat and Mass Transfer, 30(7), 1987, p. 1343-1350. DOI:10.1016/0017-9310(87)90166-9

[33] Bomberg, M.: Moisture flow through porous building materials. Dissertation, University of Lund, Sweden, 1974.

[34] Luikov, A. V.: Systems of differential equations of heat and mass transfer in capillary - porous bodies. Journal of Heat and Mass Transfer, 18(1-A), 1975, p. 1-14. DOI:10.1016/0017-9310(75)90002-2,

[35] Holm, A., Künzel, H.M.: Two-dimensional transient heat and moisture simulations of rising damp with WUFI-2D. Proceedings of 2nd International Conference on Building Physics, Leuven, Belgium, 2003, p. 363-367.

[36] Krus, M.: Moisture transport and storage coefficients of porous mineral building materials, Theoretical principles and new test methods, Fraunhofer IRB Verlag, Stuttgart, Germany, 1996. 